Article

\title{
Effect of Flavonoid-Coated Gold Nanoparticles on Bacterial Colonization in Mice Organs
}

\author{
Sundus Riaz ${ }^{1,2}$, Nosheen Fatima Rana ${ }^{1, *}$, Irshad Hussain ${ }^{3}$, Tahreem Tanweer ${ }^{1}$, Afrah Nawaz ${ }^{1}$, \\ Farid Menaa ${ }^{4}(0)$, Hussnain A. Janjua ${ }^{5}$, Tahseen Alam ${ }^{5}$, Amna Batool ${ }^{1}$, Ayesha Naeem ${ }^{1}$, \\ Maryam Hameed ${ }^{1}$ and Syed Mohsin $\mathrm{Ali}^{1}$ \\ 1 Department of Biomedical Engineering and Sciences, School of Mechanical \& Manufacturing Engineering, \\ National University of Sciences \& Technology, Islamabad 44000, Pakistan; \\ sundusriaz_fuuast@yahoo.com (S.R.); ttanveer.pg@smme.edu.pk (T.T.); \\ anawaz.bmes16smme@student.nust.edu.pk (A.N.); abatool.phd20sme@student.nust.edu.pk (A.B.); \\ anaeem.phd19bmessmme@student.nust.edu.pk (A.N.); maryam_hameed@outlook.com (M.H.); \\ sali.bmes17smme@student.nust.edu.pk (S.M.A.) \\ 2 Ministry of National Food Security and Research, Pakistan Agricultural Research Council, \\ Karachi 75270, Pakistan \\ 3 School of Science and Engineering, Lahore University of Management Sciences, Lahore 54000, Pakistan; \\ ihussain@lums.edu.pk \\ 4 Department of Internal Medicine and Nanomedicine, California Innovations Corporation, \\ San Diego, CA 92093, USA; dr.fmenaa@gmail.com \\ 5 Atta Ur Rahman School of Applied Biosciences, National University of Sciences \& Technology, \\ Islamabad 44000, Pakistan; principal-asab@nust.edu.pk (H.A.J.); tahseen260@gmail.com (T.A.) \\ * Correspondence: nosheen.fatima@smme.nust.edu.pk; Fax: +92-9085-6001
}

Received: 16 June 2020; Accepted: 28 July 2020; Published: 7 September 2020

\begin{abstract}
Multidrug resistance (MDR) has been a potentiator for the exploration of antibiotics. Nano drug delivery systems have opened new avenues to overcome this challenge. Although antibacterial nanocarriers are extensively realized, their effect on the bacteria residing inside the tissues and their toxicity is rarely explored. This study investigated the effects of flavonoid coated gold nanoparticles (FAuNPs) on the colonization of Enterococcus faecalis in the mouse liver and kidneys. Flavonoids were extracted from the leaves of Berberis lycium Royle and used to stabilize gold following a green synthesis approach. FAuNPs were characterized by ultraviolet-visible (UV-Vis) spectroscopy, Fourier-transform infrared spectroscopy (FTIR), scanning transmission electron microscopy (STEM), X-ray powder diffraction (XRD), and energy-dispersive X-ray spectroscopy (EDS). FAuNPs showed significantly higher reduction in bacterial counts in in-vitro and in-vivo in mice organs as compared to the free flavonoids owing to their biocompatibility and effectiveness.
\end{abstract}

Keywords: flavonoids; Berberis lycium; Enterococcus faecalis; drug delivery; infectious diseases

\section{Introduction}

Functional nanoparticles (NPs) have a wide range of medical applications that encompasses a broad spectrum of fields, including imaging, molecular diagnosis, and targeted drug delivery [1,2]. As drug nanocarriers, they move inside the body to repair damaged tissues, cross the cell barriers, and access those cells and tissues where other drugs/antibodies cannot reach in appropriate concentrations [2]. Their superior features are due to high surface area-to-volume ratio, small size, stability, and biocompatibility [2,3].

The history of the gold nanoparticles (AuNPs) for the delivery of antibacterial agents dates to more than a decade. Various stable complexes of antibiotics with colloidal gold have been developed. These 
include gold complexes with vancomycin, ciprofloxacin, and fluorouracil [4-6]. However, ampicillin, kanamycin, streptomycin, and many other antibiotics form unstable complexes with gold [7-9]. Later, gold nanoparticles functionalized with ampicillin [10,11], vancomycin [12], and lysozyme [13] have been reported against various strains, such as Pseudomonas aeruginosa, Enterobacter aerogenes, and multidrug resistance (MDR) Staphylococcus aureus.

The hard bacterium, Enterococcus faecalis, is an opportunistic pathogen that can withstand high environmental stresses [14]. Despite being mammalian gut residents, it also causes nosocomial infections such as urinary tract infection (UTI), bacteremia, surgical wound infection, and endocarditis [15]. Its characteristic feature resides in its acquired and intrinsic resistance against main groups of antibiotics such as aminoglycosides, $\beta$-lactams, cephalosporins, glycopeptides, tetracyclines, and trimethoprim-sulfamethoxazole $[16,17]$. This MDR is manifested by mutations or by the horizontal exchange of foreign genetic material through the transfer of plasmids and transposons [18]. Antibiotic development against Enterococci is, therefore, an active and challenging research area.

Various nanocarrier systems were documented to be effective against E. Faecalis. These include gold nanorods for phototherapy [1], vancomycin bound biogenic AuNPs [19], calcium hydroxide NPs [20], chitosan NPs [21], Ag-Ca-Si mesoporous NPs [22], silver NPs [23], and polysaccharide-maghemite composite NPs [24]. However, these studies are focused on in-vitro antibacterial activity. NPs stability and activity under physiological conditions are also a matter of interest as many factors can alter the inherent antibacterial activity of NPs, such as $\mathrm{pH}$ and temperature [25]. Besides, plasma proteins and plasma components can also interact with the NPs surface, and this can affect their biodistribution [26-28], cellular uptake, and bioactivity [29-31]. Recently, a few in vivo studies have been carried out that include combined therapy of silver NPs, and visible blue light against Pseudomonas [32], quercetin loaded PLGA for Escherichia coli [33], and tridecaptin-antibiotic conjugates against Klebsiella pneumoniae [34].

AuNPs are not considered as antibacterial agents individually; however, when conjugated with small active substances (e.g., antibiotics and antibodies), they usually exhibit more potent antimicrobial activity [4-6]. Plant, bacterial, fungal, yeast and algal extracts were frequently used for the preparation of bioactive AuNPs according to previous studies. [35-37]. The bioactive compounds in these extracts not only reduce gold $\left(\mathrm{Au}^{+3}\right)$ but also impart characteristic bioactive properties to these NPs [38]. Flavonoids are one of the extensively studied bioactive secondary metabolites from plants. The antibacterial activity of Flavonoids is ascribed to intracellular targeting such as inhibition of bacterial enzymes, damage to cytoplasmic membranes and cell wall components, inhibition of the bacterial efflux pump, and disruption of energy metabolism pathways [39]. Flavonoids can be extracted from Berberis lycium Royle, a spiny shrub prevalent in milder climates and subalpine regions. They are commonly used to treat a wide variety of human pathologies in the Pakistan, India, and Bangladesh Indian Himalayan Region. The phytochemical analysis of B. Lycium plant parts indicated the presence of important contents, including flavonoids, phenols, alkaloids, terpenoids, tannin, fat, and resin [40].

Moreover, its leaves and fruits contain a high amount of different nutritive components such as vitamin C, calcium, sulfur, protein, fiber, fat, palmitine, and berberine [40]. Importantly, B. lycium roots contain berberine, a quaternary ammonium salt from the protoberberine group of benzylisoquinoline alkaloids, which is reported for wide medicinal applications [40]. However, the bioactivities of leaves of this plant have not yet been investigated. Therefore, the present research focuses on the green synthesis of flavonoid-coated gold nanoparticles (FAuNPs) from methanol extracts of B. lyceum, its physical characterization, and the determination of its potential effect on colonization of E. faecalis both in vitro and in vivo. Herein, the biosynthesized AuNPs exhibit special antibacterial properties due to their stabilization by flavonoids. To the best of our knowledge, this is the first in-vivo study that investigates the antibacterial activity of NPs against Gram-positive bacterial colonization in mice organs such as liver and kidneys. 


\section{Materials and Methods}

B. lycium leaves were sampled from Patriata, Murree, Pakistan. Chemicals were purchased from Sigma-Aldrich (St Louis, MO, USA), except where stated. Tetrachloroauric acid trihydrate $\left(\mathrm{HAuCl}_{4} \cdot 3 \mathrm{H}_{2} \mathrm{O}\right)$ was purchased from Merk (Münch, Germany). All protocols employed were approved by the Internal Review Board (IRB), Department of Biomedical Engineering and Sciences, School of Mechanical and Manufacturing Engineering, National University of Sciences and Technology (NUST).

\subsection{Bacterial Strains}

Gram-positive bacterial strains used in the study included E. faecalis JH2-2 (derived from the parental strain JH2) [41], Bacillus cereus (soil isolates), and S. aureus (ATCC 6538). Gram-negative strains included P. aeruginosa (ATCC 9027), Salmonella Typhi (ATCC 6539), and E. coli (ATCC 8739).

\subsection{Flavonoid Extraction}

Flavonoids were extracted using Soxhlet extractor (Sigma-Aldrich, St Louis, MO, USA) from B. lycium leaves in $80 \%$ methanol for $24 \mathrm{~h}$. Methanol was subsequently evaporated by vacuum. The aqueous fraction was extracted with petroleum ether $\left(40-60{ }^{\circ} \mathrm{C}\right)$, ethyl acetate, and diethyl ether [42] (Figure S1). Free flavonoids (FF) are aglycones, while in naturally occurring conjugated flavonoids (CF), most commonly as glycosylated and methylated derivatives, the fatty acid carbon chain is linked onto the primary - $\mathrm{OH}$ group on the glucose moiety of the flavonoids. Flavonoids screening was performed using Shinoda's Test optimized by Mir et al. (2013) and Inalegwu and Sodipo (2013) [43,44]. FF and CF were dried using a rotary evaporator (Buchi Rotavapor R-200 system, Marshal Scientific, Cambridge, US).

\subsection{Green Synthesis of FAuNPs}

The solution of $\mathrm{CF}$ concentrated to $1 \mathrm{mg} / \mathrm{mL}$ in distilled water was dropwise added to $1 \mathrm{mM}$ tetrachloroauric acid $\left(\mathrm{HAuCl}_{4}\right)$. Optimization was rendered employing varying Flavonoid / $\mathrm{HAuCl} 4$ formulations ratios (1:1, 1:2, 1:3, 1:4, and 1:5). These formulations were kept at different varying $(25,40$, $50,60,70,80$, and $100^{\circ} \mathrm{C}$ ) with constant magnetic stirring for $4 \mathrm{~h}$. The $\mathrm{pH}$ of the formulations was adjusted to $4,6,8$, and 10 using strong $\mathrm{HCl}$ and $\mathrm{NaOH}$.

NPs were collected by centrifugation at $11,000 \times g$ for $10 \mathrm{~min}$. FAuNPs were lyophilized by means of a freeze dryer (EYELA FDU-1000, Tokyo, Japan) for $24 \mathrm{~h}$ at $15 \mathrm{~Pa}$. The concentration of AuNPs was evaluated with the help of Beer's Law, i.e.,:

$$
A=E \times I \times C
$$

where, $A$ is the absorbance, $E\left(\mathrm{M}^{-1} \mathrm{~cm}^{-1}\right)$ is the molar extinction coefficient, $I$ is the path length $(\mathrm{cm})$, and $C$ is the concentration.

The UV-vis absorption spectra were recorded in the range of 300-800 nm. The extinction coefficient was obtained from the standard curve.

\subsection{Physical Characterizations of FAuNPs}

The FAuNPs synthesized in the study were characterized by UV-Vis spectroscopy, FTIR spectroscopy, XRD, and scanning transmission electron microscopy (STEM). Spectrophotometric analyses were carried out by UV-2800 BMS Scientific Technical Corporation (PVT) Ltd. Spectrophotometer (Shanghai, China). For FTIR analysis, the Perkin Elmer spectrum 100 instruments (Waltham, MA, USA) were used, and the spectra were recorded in the range of $4000-400 \mathrm{~cm}^{-1}$. XRD of FAuNPs was done using the scanning mode on WinX'POW. The X-ray diffractometer system (STOE: theta/theta, Darmstadt, Germany) functioned at $40 \mathrm{kV}$ and a current of $30 \mathrm{~mA}$ with $\mathrm{Cu} \mathrm{K} \alpha$ radiation $\left(1 \frac{1}{4} 1.54064^{\circ} \mathrm{A}\right) . \mathrm{STEM} / \mathrm{EDAX}$ (energy-dispersive analysis of X-rays) of FAuNPs was performed with a 
FEI NOVA, NanoSEM 450 (Hillsboro, Oregon, US) equipped with a STEM detector operated at $120 \mathrm{keV}$. STEM images of FAuNPs were then managed through Image-J software 1.8.0_112, windows (64 bit) version (NIH and LOCI, Madison, WI, USA) for their histogram analysis.

\subsection{In-Vitro Stability of FAuNPs}

FAuNPs were centrifuged at $10,000 \times g$ for a period of $10 \mathrm{~min}$; the subsequent pellets were then resuspended in 2, 3, and $4 \mathrm{M} \mathrm{NaCl}$ solution and set aside at $37^{\circ} \mathrm{C}$ for $24 \mathrm{~h}$ [45]. The impact of heat on FAuNPs was determined by heating $10 \mathrm{~mL}$ of FAuNPs at $100{ }^{\circ} \mathrm{C}$ for $30 \mathrm{~min}$.

\subsection{Antibacterial Susceptibility of Flavonoids by Qualitative Method}

The antibacterial activity of FF, CF and crude extracts (CE) against various bacteria was performed using the Kirby-Bauer method. [46]. Disks were loaded with $10 \mu \mathrm{L}$ of FF, CF, and CE separately against different Gram-positive (E. faecalis, B. cereus, and S. aureus) and Gram-negative bacteria (P. aeruginosa, S. typhi, and E. coli). The respective inhibition zone (ZI) was measured after incubation at $37^{\circ} \mathrm{C}$ for $24 \mathrm{~h}$.

\subsection{Minimum Inhibitory Concentration (MIC) and Minimum Bactericidal Concentration (MBC) of CF and FAuNPs Against E. faecalis}

The MIC of CF and FAuNPs against $E$. faecalis was determined using a standard broth microdilution method after $24 \mathrm{~h}$ of incubation at $37^{\circ} \mathrm{C}$ with an inoculum of approximately $10^{6} \mathrm{CFU} / \mathrm{mL}$. Column 1 functioned as a negative control which constituted only the medium, whereas column 2 functioned as a positive control, i.e., medium-plus bacterial inoculum. The MBC test was performed via inoculation of MIC broth on culture plates containing nutrient agar. The lowest concentration that showed less than $50 \%$ of visible bacterial growth after $24 \mathrm{~h}$ was taken as MBC.

\subsection{Hemolysis Assay}

The hemolytic activity was estimated according to the method described by Muhammad et al. (2016) [47]. Triton X-100 (0.5\%) (Sigma Aldrich, St Louis, MO, USA) was used as a positive control. The absorbance was measured using a UV-2800 BMS Scientific Technical Corporation (PVT) Ltd. Spectrophotometer (Shanghai, China) at $550 \mathrm{~nm}$.

\subsection{Colonization of E. faecalis in BALB/c Mice}

BALB/c mice $(n=30)$ were purchased from the National Institute of Health $(\mathrm{NIH})$, Islamabad. Eight weeks-old BALB/c female mice (25-30 g) were kept under temperature $25 \pm 2{ }^{\circ} \mathrm{C}$ and provided with a natural light $(10 \mathrm{~h})$ and dark cycle $(14 \mathrm{~h})$. Autoclaved tap water and a standard diet ad libitum were given to mice.

A well-established intravenous infection model was used for bacterial colonization in mice tissues [14-16]. Preculture was prepared in GM17 broth at $37^{\circ} \mathrm{C}$ [14]. Brain heart infusion medium augmented with $40 \%$ filter-sterilized serum was injected with $100 \mu \mathrm{L}$ of preculture and were incubated at the temperature of $37^{\circ} \mathrm{C}$ with shaking while waiting for the $\mathrm{OD}_{600}$ to reach at 0.8 . Cultures were centrifuged, and the subsequent pellets were washed with phosphate buffer saline (PBS) $1 \mathrm{M}$ (composed of $\mathrm{NaCl}, \mathrm{KCl}, \mathrm{Na}_{2} \mathrm{HPO}_{4}$, and $\mathrm{KH}_{2} \mathrm{PO}_{4}$, accustomed to $\mathrm{pH} 7.4$ with $\mathrm{HCl}$ ). It is then suspended in sterile PBS. Bacterial suspensions of $100 \mu \mathrm{L}\left(1 \times 10^{9}\right.$ cells $\left./ \mathrm{mL}\right)$ were injected intravenously (tail vein) in each of the twenty-five female mice. The remaining five mice were untreated and thus served as negative controls.

\subsection{In Vivo Antibacterial Activity of CF and FAuNPs}

To assess the in-vivo antibacterial activity, both CF and FAuNPs were dissolved in PBS. Two infected groups (5 mice each) were treated with CF (5 mg/kg and $10 \mathrm{mg} / \mathrm{kg})$, and the other two groups 
were treated with FAuNPs $(400 \mu \mathrm{g} / \mathrm{kg}$ and $5 \mathrm{mg} / \mathrm{kg}$ ). CF and FAuNPs were deliveredin the tail vein once a day for eight days starting from the seventh day of infection until the day of the challenge.

\subsection{Statistical Analysis}

Statistical analysis such as the average, standard deviation, and multiple group comparison analysis by using a one-way ANOVA was calculated by Graph pad prism (Graphpad, San Diego, CA, USA).

\section{Results and Discussion}

It is well assumed that NPs carrying antibiotics are found to be quite effective against resistant bacteria [48]. This is particularly due to the striking features of NPs attributed to their size and unique physiochemical properties at the nanoscale that help them to evade drug efflux pumps. Flavonoids, albeit depending upon their type and structure, often display poor absorption and bioavailability [49]. One way to combat the above constraints is to use drug nanocarriers [2,41]. For their development, flavonoids can act as reducing as well as a capping agent for the synthesis of metallic NPs. Green synthesis is, therefore, a better option than using toxic reducing agents, especially for biomedical applications.

Flavonoids were used for a range of medicinal applications, such as antibacterial, antiviral, antioxidative, anti-inflammatory, anticancer, cardio-protective, skin-protective, and antidiabetic activities [50]. Flavonoids can be obtained from B. lycium, which is a known medicinal plant containing a variety of bioactive constituents [40]. Medicinal plants are a good source of potent and safe natural extracts that could act as adjuvants or even be an alternative to costly antibiotics against which microbes are becoming resistant day by day. Moreover, these extracts are cost-effective and work effectively against a variety of microbes, including bacteria, fungus, and viruses [51-53].

\subsection{Antimicrobial Activity of Flavonoids}

Since B. lycium leaves and their flavonoids have not been investigated before, we initially tested flavonoids against different Gram-positive (B. cereus, S. aureus, and E. faecalis) and Gram-negative bacteria (P. aeruginosa, S. typhi, and E. coli). Chloramphenicol and DMSO were utilized as positive and negative controls, correspondingly. Antimicrobial activity (ZI; $500 \mu \mathrm{g} /$ disc) of FF, CF, and CE are presented in Figure 1. Both FF and CF showed maximum inhibition against Gram-negative bacteria, compared to CE. Among Gram-positive bacteria, significantly higher inhibition $(p<0.0001)$ against E. faecalis was observed for CF compared to that of FF. No statistically significant difference $(p>0.05)$ was noticed amongst the $\mathrm{CF}$ and chloramphenicol for this activity. Therefore, $\mathrm{CF}$ was used for the further steps of this study. Additionally, this research supports that the mechanism of action of flavonoids is well dependent on the type of flavonoids [49,54].

\subsection{Synthesis and Physical Characterizations of FAuNPs}

The green synthesized FAuNPs used in the study were characterized and analyzed by UV-Vis spectroscopy. FTIR spectroscopy, XRD, STEM, and EDS analysis (EDXA).

\subsubsection{Impact of Physico-Chemical Parameters on FAuNPs Synthesis and Its Stability}

As shown in Figure 2a, variation in the $\lambda$ max was observed when the different concentrations of $\mathrm{HAuCl}_{4}$ salt were utilized for the synthesis of FAuNPs. The absorption intensity gradually increased at 1:3 (Au:flavonoid), indicating the complete reduction of gold ions $\left(\mathrm{Au}^{+}\right)$. The impact of temperature and $\mathrm{pH}$ on the formation of FAuNPs are presented in Figure $2 \mathrm{~b}, \mathrm{c}$, respectively. Maximum absorbance was obtained for $\mathrm{pH} 4$ and a temperature of $70{ }^{\circ} \mathrm{C}$. Thus, these parameters were considered as optimal conditions for the formation of FAuNPs. 


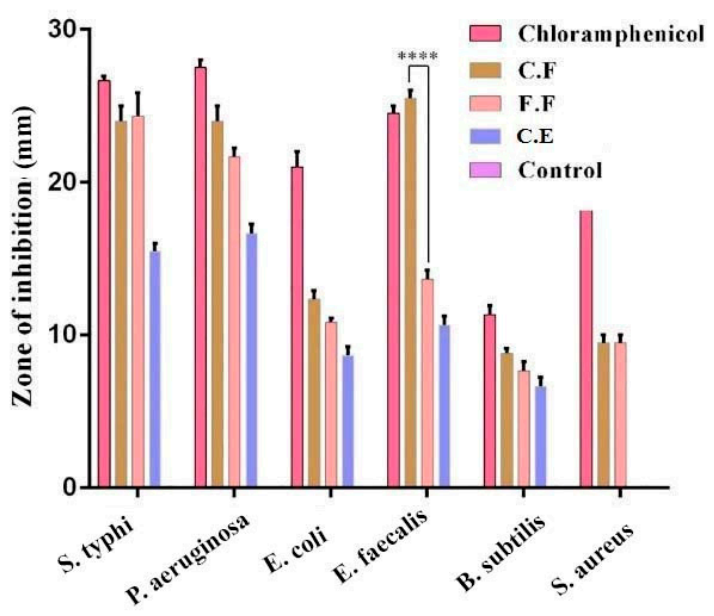

Figure 1. Antimicrobial activity (zone of inhibition; $500 \mu \mathrm{g} / \mathrm{disc}$ ) of free (FF) and conjugated flavonoids (CF) and crude extracts (CE) against Gram-negative and Gram-positive bacteria. ${ }^{* * * *} p \leq 0.0001$.
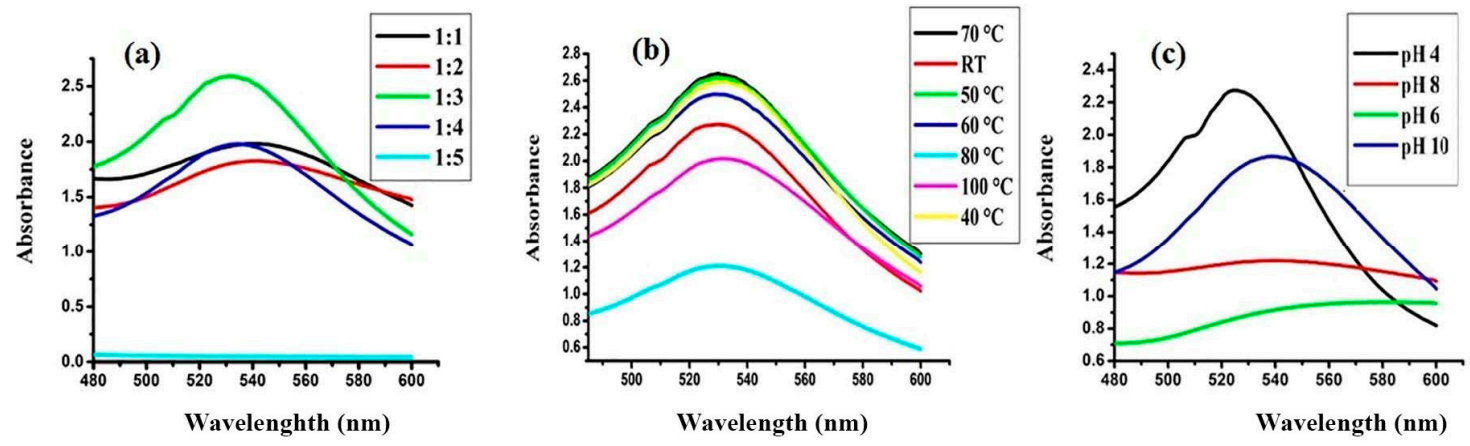

Figure 2. UV-Vis spectra of flavonoid coated gold nanoparticles (FAuNPs) synthesis at different (a) flavonoid/ $\mathrm{HAuCl}_{4}$ ratios, (b) temperature, and (c) $\mathrm{pH}$.

Concentration of FAuNPs in solution was determined using Beer's law. The UV-Vis spectra showed maximum absorbance (2.6) at $529 \mathrm{~nm}$. With 2.6 absorbance, $3 \times 10^{9} \mathrm{M}^{-1} \mathrm{~cm}^{-1}$ and $1 \mathrm{~cm}$ path length, the concentration of nanoparticles was calculated to be $8.6 \times 10^{-10} \mathrm{M}$. The calculated concentration may have some inaccuracy owing to the polydispersity of the synthesized NPs. The calculated concentration is presented under the assumption that the prepared NPs are monodispersed.

As shown in Figure 3a, the effect of temperature on the surface plasmon resonance (SPR) peak of FAuNPs allowed us to conclude that the effect of temperature on FAuNPs is negligible, has a minute reduction in absorbance while the surface plasmon peak do not shifted, and no aggregation observed.
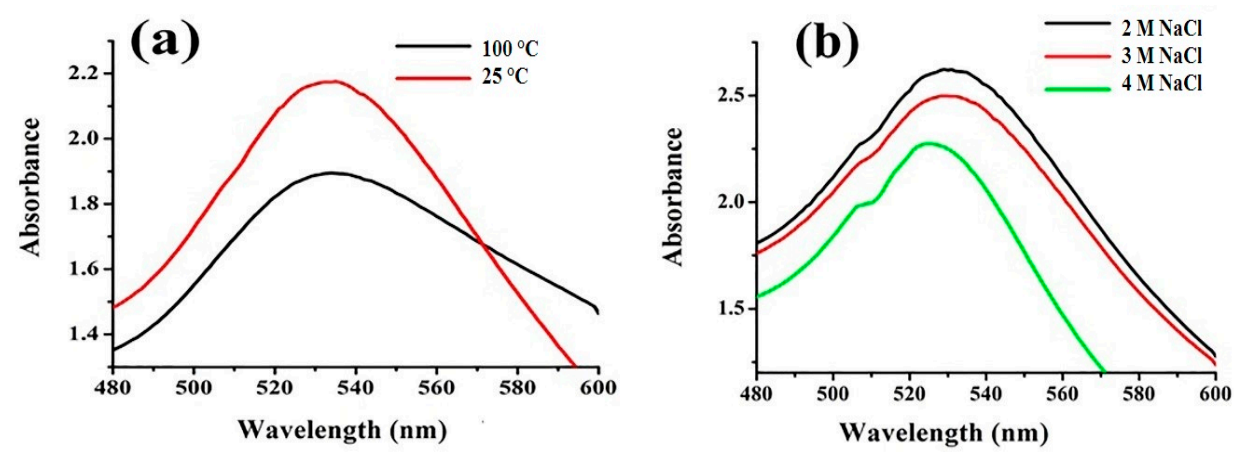

Figure 3. Effect of (a) temperature and (b) salt concentration on the stability of FAuNPs. 
Figure $3 \mathrm{~b}$ shows the effect of varying concentrations of $\mathrm{NaCl}(2-4 \mathrm{M})$ on the SPR peak of FAuNPs. No effect on FAuNPs was noted by increasing the concentration of salt from 2 to $4 \mathrm{M} \mathrm{NaCl}$ solution even after a few weeks. It was observed that a higher concentration of salt increased the full width at half maximum (FWHM), or $\lambda$ max also decreased, which results in reducednanoparticles stability. This decrease in $\lambda$ max may be attributed to the aggregation of nanoparticles which was increased by $\mathrm{Cl}^{-1}$ ions. From these findings, it is inferred that gold nanoparticles are much more stable in water for long-term stability than in $\mathrm{NaCl}$ solution.

\subsubsection{FTIR Analysis of CF and FAuNPs}

FTIR spectroscopy data validated the conjugation of flavonoids with AuNPs since typically observed absorbance bands associated to flavonoids were observed in the area of 500-3500 $\mathrm{cm}^{-1}$ (Figure 4). Absorbance band at $3398 \mathrm{~cm}^{-1}$ can be ascribed to O-H stretching, 2960-2850 $\mathrm{cm}^{-1}$ to $\mathrm{C}-\mathrm{H}$ stretching $\left(\mathrm{CH}_{2}, \mathrm{CH}_{3}\right), 1652 \mathrm{~cm}^{-1}$ to $\mathrm{C}=\mathrm{O}$ stretching, $1600 \mathrm{~cm}^{-1}$ to $\mathrm{C}=\mathrm{C}$ stretching (aromatic), $1554 \mathrm{~cm}^{-1}$ to $\mathrm{C}-\mathrm{C}$ stretching (aromatic), $1300 \mathrm{~cm}^{-1}$ to $\mathrm{C}-\mathrm{O}$ stretching (ether linkage), $1210 \mathrm{~cm}^{-1}$ to $\mathrm{C}-\mathrm{O}$ stretching (polyols), and $1100 \mathrm{~cm}^{-1}$ to $\mathrm{C}-\mathrm{OH}$ stretching, while absorbance bands at $909 \mathrm{~cm}^{-1}$ and $850 \mathrm{~cm}^{-1}$ were both assigned to $\mathrm{C}-\mathrm{H}$ bending vibrations out of plane $[41,48]$.

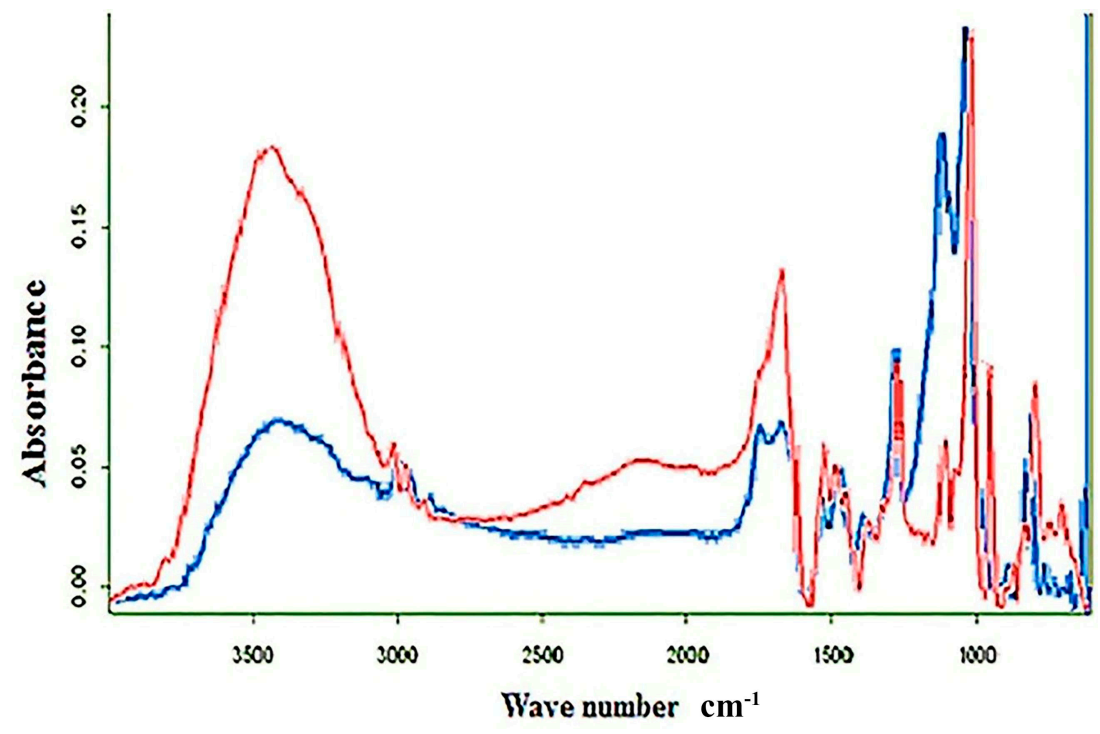

Figure 4. FTIR spectra of CF (red) and FAuNPs (blue).

\subsubsection{XRD Analysis of FAuNPs}

The crystal structure of the biosynthesized FAuNPs was investigated by XRD. The Bragg reflection suggested that AuNPs were specifically indexed to a face-centered cube (FCC) crystal structure (Figure 5). In the XRD spectra of FAuNPs, peaks were achieved at $2 \theta$ values of $37^{\circ}, 44^{\circ}, 64^{\circ}$ and $77^{\circ}$ pertaining to the FCC gold reflections of 111, 200, 220 and 311, respectively. This pattern is perfectly suited to JCPDS card number 00-002-1095 [20]. The high intense peak (200) of FCC gold was detected in the sample. Peaks intensity exhibited a high degree of FAuNP crystal structure. The broad peaks of diffraction are attributable to the small size of the crystal.

From the Scherrer equation, the mean crystallite size of the FAuNPs was calculated [55].

$$
B=\frac{0.93 \lambda}{\beta \cos \theta}
$$

where $\lambda$ is the wavelength of the X-rays incident $(\lambda=1.54060 \AA), \beta$ is the full width of the 200 diffractions half maximum and $\theta$ is the diffraction angle. The FAuNPs had a diameter of $37.6 \mathrm{~nm}$. 


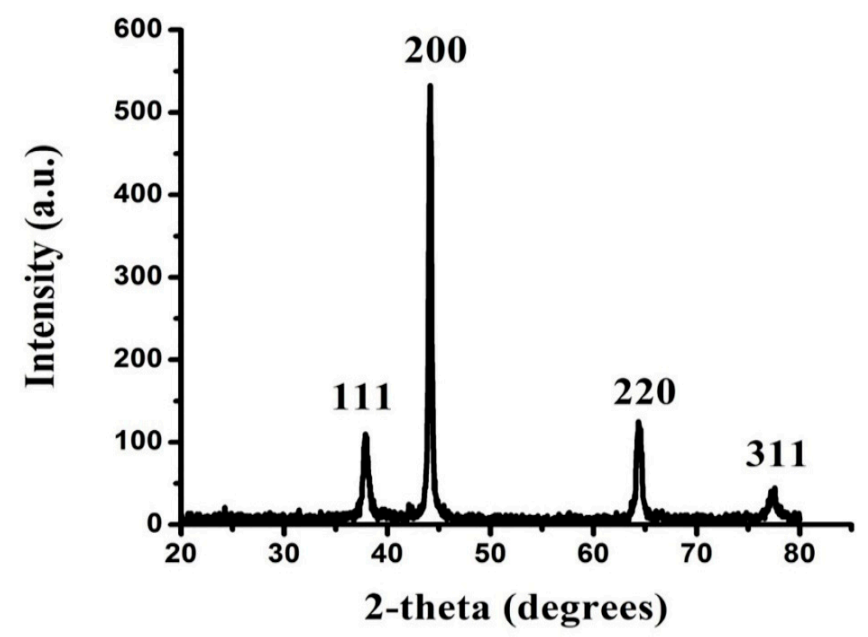

Figure 5. XRD analysis of FAuNPs.

\subsubsection{STEM Analysis of FAuNPs}

The size, shape and morphology of FAuNPs were analyzed using STEM (Figure 6). The FAuNPs comprised of spherical NPs (Figure 6a) measuring 3 to $50 \mathrm{~nm}$ in size (Figure 6b). Particle size distribution calculated from STEM image fitted with the Gaussian function indicating an average size of NPs of $23 \mathrm{~nm}$ (Figure 6b).

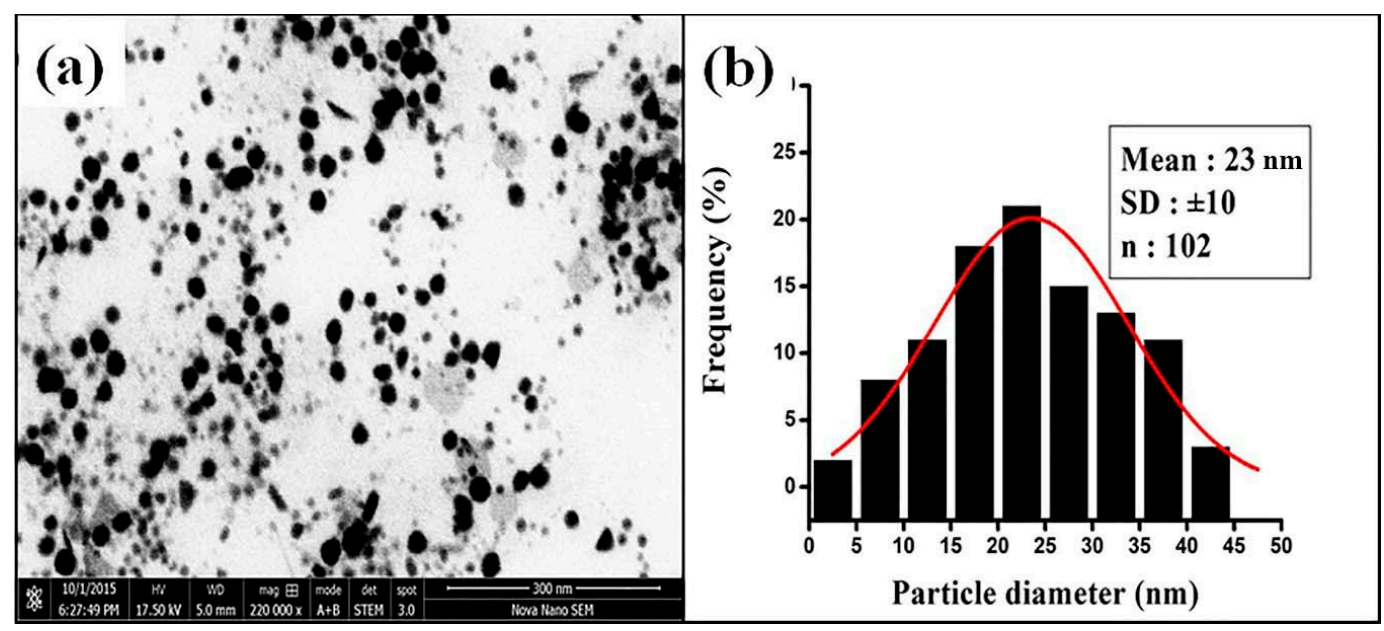

Figure 6. (a) Scanning transmission electron microscopy (STEM) image of FAuNPs and (b) particle size distribution of FAuNPs.

\subsubsection{EDS Analysis (EDAX) of FAuNPs}

The elemental composition of FAuNPs was studied by EDXA. Figure 7 showed the presence of Au at 4.42 wt \%.

\subsection{In Vitro Antibacterial Activity of FAuNPs}

Enterococci are microorganisms with exceptional abilities, allowing them to survive in harsh environments. Thereby, the intrinsic and acquired ruggedness enable E. faecalis among Enterococcus sp. to be considered as the most persisting nosocomial causing pathogen [18]. In addition to this, reduced bactericidal concentration and activity of antibiotics to the site of the infection is also the culprit for radical-induced mutagenesis, a further supporter for MDR [56].

The disk diffusion test was conducted as an initial study to screen the antibacterial activity of flavonoids. Further investigation was done to determine the MIC and MBC values of CF and FAuNPs. 
The lowest concentration of an antimicrobial to inhibit the growth of the bacteria was considered as MIC, while the lowest concentration that allowed no growth after subculturing from MIC was regarded as MBC. This study showed that MIC for CF and FAuNPs against E. faecalis was $500 \mu \mathrm{g} / \mathrm{mL}$ and $25 \mu \mathrm{g} / \mathrm{mL}$, respectively. The MBC of CF was about 2-fold higher than the final MIC $(1.75 \mathrm{mg} / \mathrm{mL})$, whereas the MBC for FAuNPs against E. faecalis was quite similar to their MIC (i.e., $25 \mu \mathrm{g} / \mathrm{mL}$ ). At this concentration, less than $50 \%$ of bacterial growth was observed, indicating the potential of FAuNPs as a decent antibacterial agent at much lesser concentrations.

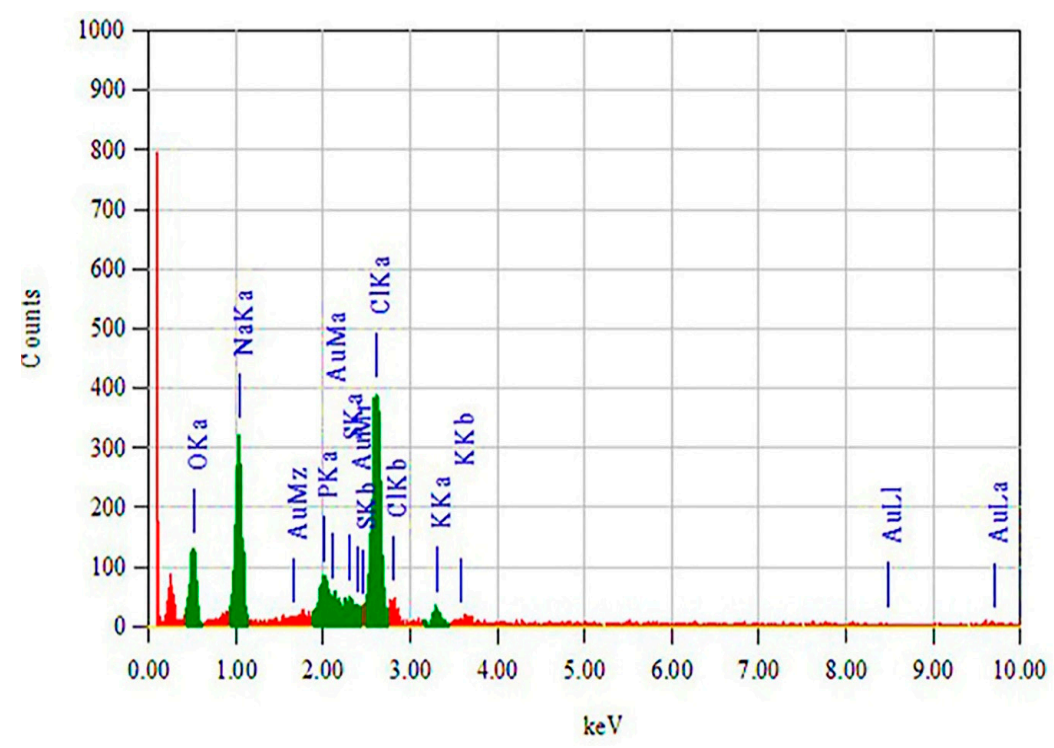

Figure 7. EDS analysis (EDXA) of FAuNPs.

\subsection{Hemolysis Assay}

Hemolysis is the breakdown of red blood cells (RBCs) and the discharge of their contents into the environment. So, when FAuNPs first enter the blood, they get in contact with RBCs [57]. To assess the impact of FAuNPs on RBCs, the hemolysis assay was performed to measure the hemolytic rate (\%) when various concentrations (range: 0-150 $\mu \mathrm{g} / \mathrm{mL}$ ) of CF or FAuNPs were used. Hemolysis assay indicated that FAuNPs were more hemocompatible compared to $\mathrm{CF}$, which the effect was seen as highly significant ${ }^{* *} p<0.01$ ) when concentrations were used over $50 \mu \mathrm{g} / \mathrm{mL}$ (Figure 8). Hemolytic behavior of FAuNPs at different concentrations remained less than 5\%, and according to ISO/TR 7406, this concentration is declared as safe.

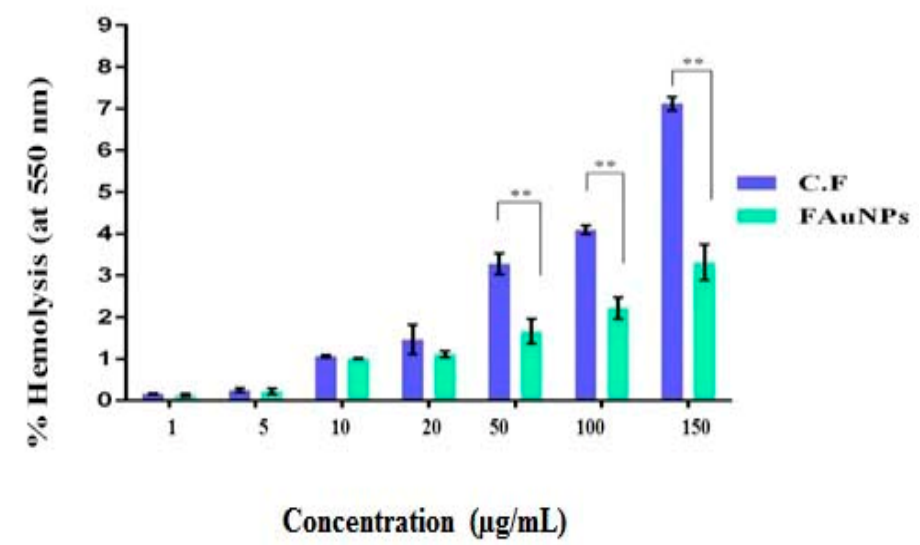

Figure 8. Hemolytic activity of CF and FAuNPs. ${ }^{* *} p<0.01$. 


\subsection{In Vivo Anticolonizing Potential of CF and FAuNPs in Infectious Mice Model}

E. faecalis infection model was prepared by intravenous (IV) administration of bacterial cells to study the anticolonizing activity of FAuNPs. The respective MIC dose of CF (i.e., $500 \mu \mathrm{g} / \mathrm{mL}$ ) and FAuNPs (i.e., $25 \mu \mathrm{g} / \mathrm{mL}$ ) was administered for seven days after infection in mice. Our results showed that diseased mice have reduced food intake and greenish feces. These symptoms were greatly improved on the 4th day of treatment with CF and the 2nd day with FAuNPs. IV administration of CF showed increased palpitation and itching in mice. This was, however, not the case with FAuNPs treatment. After a week of treatment, all mice were sacrificed, and their liver and kidneys were removed to measure the viable bacterial count. Figure 9 a,b show bacterial counts $\left(\log _{10} \mathrm{CFU} / \mathrm{gm}\right.$ of the organ) in infected kidneys and liver, respectively.
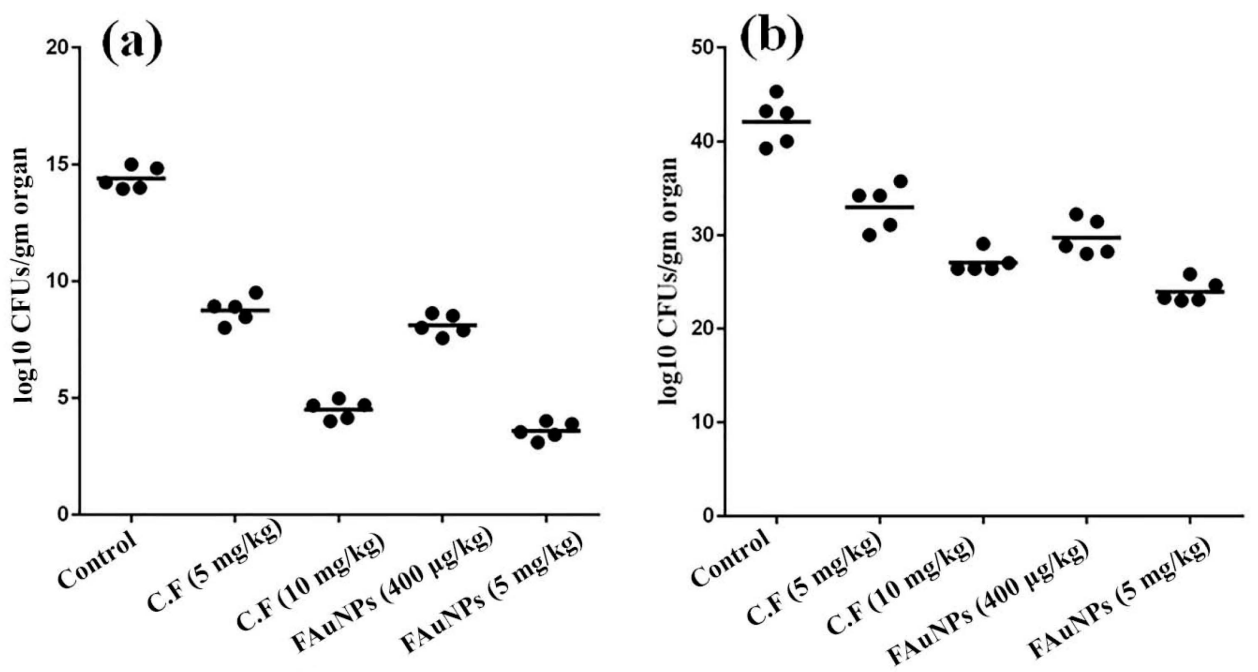

Figure 9. Effect of CF and FAuNPs, at respective MIC, on the colonization of E. faecalis in the kidneys (a) and liver (b) of mice.

The in-vivo results showed that the mice treated with FAuNPs have significantly reduced bacterial colonization in the liver $(p=0.001)$ and kidneys $(p=0.001)$ when compared to that of C.F-treated mice. No effect was found on the size, texture, and weight of the liver and kidneys by CF and FAuNPs-treated mice as compared to the normal mice. To the best of our knowledge, this is the first study that investigated the in-vivo activity of flavonoids against bacterial colonization in mice.

\section{Conclusions and Perspectives}

The enhanced antibacterial activity of bioactive compounds in nanoformulations has been extensively studied. However, most of such studies are focused on in-vitro aspects. The present study was focused on a green synthesis and characterizations of FAuNPs, which were further assessed for their in-vitro and in-vivo antibacterial potential against Gram-positive bacterium E. faecalis. The FAuNPs were successfully synthesized, and different physical characterizations confirmed their formation. The synthesized FAuNPs were sphere-shaped shaped with a $23 \mathrm{~nm}$ diameter average size. The results for optimizations revealed that a 1:3 ratio of $\mathrm{Au}$ and flavonoid, a $\mathrm{pH}$ of 4 , and a temperature of $70{ }^{\circ} \mathrm{C}$ are effective conditions for FAuNPs formation. Stability results showed that temperature had negligible effect on stability of optimized FAuNPs. However, FAuNPs cannot remain stable in salt solution. These FAuNPs when tested for antibacterial activity showed enhanced activity against E. faecalis with MIC of $25 \mu \mathrm{g} / \mathrm{mL}$. Similarly, they also showed reduced bacterial colonizing activity of E. faecalis in liver and kidneys of the mice. FAuNPs were more biocompatible owing to its reduced hemolytic behavior with varying concentrations. The results of this study conclude that FAuNPs can be very effective antibacterial agents against $E$. faecalis infections. The present study was based on a 
non-biofilm forming E. faecalis strain. In the future, further studies are required for biofilm-forming and vancomycin-resistant $E$. faecalis strains.

Supplementary Materials: The following are available online at http://www.mdpi.com/2079-4991/10/9/1769/s1, Figure S1: Extraction procedure for free and conjugated flavonoids.

Author Contributions: Conceptualization, S.R., and N.F.R.; Data curation, S.R., N.F.R., F.M., and T.T.; Formal analysis, S.R., N.F.R., F.M. and I.H.; Funding acquisition, N.F.R.; Investigation, S.R.; Methodology, S.R., F.M., H.A.J., T.A., N.F.R., A.N (Afrah Nawaz)., I.H.; Project administration, S.R., T.T., H.A.J., T.A., A.B., A.N. (Afrah Nawaz), A.N. (Ayesha Naeem), M.H., and S.M.A.; Resources, N.F.R., I.H., H.A.J., T.A., A.N (Afrah Nawaz).; Software, S.R., N.F.R., T.T. and A.B.; Supervision, N.F.R. and I.H.; Validation, N.F.R., I.H., H.A.J., F.M., A.N (Afrah Nawaz); Visualization, S.R., T.T., A.B., A.N. (Afrah Nawaz), A.N. (Ayesha Naeem), M.H., and S.M.A.; Writing-original draft, S.R., N.F.R and T.T.; Writing-review and editing, I.H., T.T., F.M., A.B., A.N. (Afrah Nawaz), A.N. (Ayesha Naeem), M.H., and S.M.A. All authors have read and agreed to the published version of the manuscript.

Funding: This research was funded by the "National Research Program for Universities (NRPU), Higher Education Commission (HEC), Pakistan; grant number 6035".

Conflicts of Interest: The authors declare no conflict of interest.

\section{Abbreviations}

\begin{tabular}{|c|c|}
\hline B. lyceum: & Berberis lycium \\
\hline C.E: & Crude extract \\
\hline C.F: & Conjugated flavonoids \\
\hline E. faecalis: & Enterococcus faecalis \\
\hline EDS: & Energy-dispersive $\mathrm{X}$-ray spectroscopy \\
\hline FAuNPs: & Flavonoid gold nanoparticles \\
\hline F.F: & Free flavonoids \\
\hline FTIR: & Fourier-transform infrared spectroscopy \\
\hline $\mathrm{HAuCl}_{4}$ : & Tetrachloroauric acid \\
\hline IV: & Intravenous \\
\hline MDR: & Multi-drug resistance \\
\hline NPs: & Nanoparticles \\
\hline RBCs: & Red blood cells \\
\hline STEM: & Scanning transmission electron microscopy \\
\hline UTI: & Urinary tract infection \\
\hline UV-Vis: & Ultraviolet-visible \\
\hline
\end{tabular}

\section{References}

1. Dykman, L.; Khlebtsov, N. Gold nanoparticles in biomedical applications: Recent advances and perspectives. Chem. Soc. Rev. 2012, 41, 2256-2282. [CrossRef] [PubMed]

2. Menaa, F. When Pharma Meets Nano or The Emerging Era of Nano-Pharmaceuticals. Pharm. Anal. Acta 2013, 4, 223. [CrossRef]

3. Loomba, L.; Scarabelli, T. Metallic nanoparticles, and their medicinal potential. Part I: Gold and silver colloids. Ther. Deliv. 2013, 4, 859-873. [CrossRef] [PubMed]

4. Gu, H.; Ho, P.; Tong, E.; Wang, L.; Xu, B. Presenting Vancomycin on Nanoparticles to Enhance Antimicrobial Activities. Nano Lett. 2003, 3, 1261-1263. [CrossRef]

5. Rosemary, M.; MacLaren, I.; Pradeep, T. Investigations of the Antibacterial Properties of Ciprofloxacin@SiO $\mathrm{S}_{2}$. Langmuir 2006, 22, 10125-10129. [CrossRef]

6. Selvaraj, V.; Alagar, M. Analytical detection and biological assay of antileukemic drug 5-fluorouracil using gold nanoparticles as probe. Int. J. Pharm. 2007, 337, 275-281. [CrossRef]

7. Chakraborty, S.; Sahu, S.; Pramanik, P.; Roy, S. In vitro antimicrobial activity of nanoconjugated vancomycin against drug resistant Staphylococcus aureus. Int. J. Pharm. 2012, 436, 659-676. [CrossRef]

8. Grace, N.; Pandian, K. Antibacterial efficacy of aminoglycosidic antibiotics protected gold nanoparticles a brief study. Colloids and Surfaces A: Physicochem. Eng. Asp. 2007, 297, 63-70. [CrossRef]

9. Grace, N.; Pandian, K. Quinolone antibiotic-capped gold nanoparticles and their antibacterial efficacy against gram positive and gram-negative organisms. J. Bionanosci. 2007, 1, 96-105. [CrossRef] 
10. Brown, A.; Smith, K.; Samuels, T.; Lu, J.; Obare, S.; Scott, M. Nanoparticles Functionalized with Ampicillin Destroy Multiple-Antibiotic-Resistant Isolates of Pseudomonas aeruginosa and Enterobacter aerogenes and Methicillin-Resistant Staphylococcus aureus. Appl. Environ. Microbiol. 2012, 78, 2768-2774. [CrossRef]

11. Chamundeeswari, M.; Sobhana, S.; Jacob, J.; Kumar, M.; Devi, M.; Sastry, T.; Mandal, A. Preparation, characterization and evaluation of a biopolymeric gold nanocomposite with antimicrobial activity. Biotechnol. Appl. Biochem. 2010, 55, 29-35. [CrossRef] [PubMed]

12. Varisco, M.; Khanna, N.; Brunetto, P.; Fromm, K. New Antimicrobial and Biocompatible Implant Coating with Synergic Silver-Vancomycin Conjugate Action. ChemMedChem 2014, 9, 1221-1230. [CrossRef] [PubMed]

13. Chen, W.; Lin, J.; Chen, W.; Luo, L.; Wei-Guang Diau, E.; Chen, Y. Functional gold nanoclusters as antimicrobial agents for antibiotic-resistant bacteria. Nanomedicine 2010, 5, 755-764. [CrossRef]

14. Rana, N.; Sauvageot, N.; Laplace, J.; Bao, Y.; Nes, I.; Rincé, A.; Posteraro, B.; Sanguinetti, M.; Hartke, A. Redox Balance via Lactate Dehydrogenase Is Important for Multiple Stress Resistance and Virulence in Enterococcus faecalis. Infect. Immun. 2013, 81, 2662-2668. [CrossRef] [PubMed]

15. Arias, C.; Contreras, G.; Murray, B. Management of multidrug-resistant enterococcal infections. Clin. Microbiol. Infect. 2010, 16, 555-562. [CrossRef]

16. Michaux, C.; Sanguinetti, M.; Reffuveille, F.; Auffray, Y.; Posteraro, B.; Gilmore, M.; Hartke, A.; Giard, J. SlyA Is a Transcriptional Regulator Involved in the Virulence of Enterococcus faecalis. Infect. Immun. 2011, 79, 2638-2645. [CrossRef]

17. Gentry-Weeks, C.; Estay, M.; Loui, C.; Baker, D. Intravenous Mouse Infection Model for Studying the Pathology of Enterococcus faecalis Infections. Infect. Immun. 2003, 71, 1434-1441. [CrossRef]

18. Blair, M.; Webber, A.; Baylay, J.; Ogbolu, O.; Piddock, J. Molecular mechanisms of antibiotic resistance. Nat. Rev. Microbiol. 2015, 13, 42-51. [CrossRef]

19. Mohammed Fayaz, A.; Girilal, M.; Mahdy, S.; Somsundar, S.; Venkatesan, R.; Kalaichelvan, P. Vancomycin bound biogenic gold nanoparticles: A different perspective for development of anti VRSA agents. Process Biochem. 2011, 46, 636-641. [CrossRef]

20. Dianat, O.; Saedi, S.; Kazem, M.; Alam, M. Antimicrobial Activity of Nanoparticle Calcium Hydroxide against Enterococcus Faecalis: An In vitro study. Iran Endod. J. 2014, 10, 39-43.

21. Barreras, U.; Méndez, F.; Martínez, R.; Valencia, C.; Rodríguez, P.; Rodríguez, J. Chitosan nanoparticles enhance the antibacterial activity of chlorhexidine in collagen membranes used for periapical guided tissue regeneration. Mater. Sci. Eng. C 2016, 58, 1182-1187. [CrossRef] [PubMed]

22. Fan, B. Substantivity of Ag-Ca-Si mesoporous nanoparticles on dentin and its ability to inhibit Enterococcus faecalis. J. Mater. Sci. Mater. Med. 2015, 27. [CrossRef] [PubMed]

23. Wu, D.; Fan, W.; Kishen, A.; Gutmann, J.L.; Fan, B. Evaluation of the Antibacterial Efficacy of Silver Nanoparticles against Enterococcus faecalis Biofilm. J. Endod. 2014, 40, 285-290. [CrossRef] [PubMed]

24. Iconaru, S.L.; Prodan, A.M.; Motelica-Heino, M.; Sizaret, S.; Predoi, D. Synthesis and characterization of polysaccharide-maghemite composite nanoparticles and their antibacterial properties. Nanoscale Res. Lett. 2012, 7, 576. [CrossRef] [PubMed]

25. Abdel-Raouf, N.; Al-Enazi, N.M.; Ibraheem, I.B. Green biosynthesis of gold nanoparticles using Galaxaura elongata and characterization of their antibacterial activity. Arab. J. Chem. 2017, 10, S3029-S3039. [CrossRef]

26. Dwivedi, P.; Nayak, V.; Kowshik, M. Role of gold nanoparticles as drug delivery vehicles for chondroitin sulfate in the treatment of osteoarthritis. Biotechnol. Prog. 2015, 31, 1416-1422. [CrossRef]

27. Sahayaraj, K.; Rajesh, S. Bionanoparticles: Synthesis and antimicrobial applications. In Science against microbial pathogens: Communicating current research and technological advances. Badajoz Spain 2011, 23, 228-244.

28. Ehrenberg, M.S.; Friedman, A.E.; Finkelstein, J.N.; Oberdörster, G.; Mcgrath, J.L. The influence of protein adsorption on nanoparticle association with cultured endothelial cells. Biomaterials 2009, 30, 603-610. [CrossRef]

29. Dobrovolskaia, M.A.; Aggarwal, P.; Hall, J.B.; Mcneil, S.E. Preclinical Studies To Understand Nanoparticle Interaction with the Immune System and Its Potential Effects on Nanoparticle Biodistribution. Mol. Pharm. 2008, 5, 487-495. [CrossRef]

30. Manach, C.; Williamson, G.; Morand, C.; Scalbert, A.; Rémésy, C. Bioavailability and bioefficacy of polyphenols in humans. I. Review of 97 bioavailability studies. Am. J. Clin. Nutr. 2005, 81, 230S-242S. [CrossRef] 
31. Moghimi, S.M.; Hunter, A.C.; Murray, J.C. Long-circulating and target-specific nanoparticles: Theory to practice. Pharmacol. Rev. 2001, 53, 283-318. [PubMed]

32. . El-Azizi, M.M.; Din, S.N.E.; El-Tayeb, T.; Aisha, K.A. In vitro and in vivo antimicrobial activity of combined therapy of silver nanoparticles and visible blue light against Pseudomonas aeruginosa. Int. J. Nanomed. 2016, 11, 1749. [CrossRef] [PubMed]

33. Sun, D.; Li, N.; Zhang, W.; Yang, E.; Mou, Z.; Zhao, Z.; Liu, H.; Wang, W. Quercetin-loaded PLGA nanoparticles: A highly effective antibacterial agent in vitro and anti-infection application in vivo. J. Nanoparticle Res. 2015, 18, 3. [CrossRef]

34. Cochrane, S.A.; Li, X.; He, S.; Yu, M.; Wu, M.; Vederas, J.C. Synthesis of Tridecaptin-Antibiotic Conjugates with in Vivo Activity against Gram-Negative Bacteria. J. Med. Chem. 2015, 58, 9779-9785. [PubMed]

35. Kuppusamy, P.; Yusoff, M.M.; Maniam, G.P.; Govindan, N. Biosynthesis of metallic nanoparticles using plant derivatives and their new avenues in pharmacological applications-An updated report. Saudi Pharm. J. 2016, 24, 473-484. [CrossRef]

36. Oberdörster, G. Safety assessment for nanotechnology and nanomedicine: Concepts of nanotoxicology. J. Intern. Med. 2010, 267, 89-105. [CrossRef]

37. Cushnie, T.T.; Lamb, A.J. Recent advances in understanding the antibacterial properties of flavonoids. Int. J. Antimicrob. Agents 2011, 38, 99-107. [CrossRef]

38. Ateeq, M.; Shah, M.R.; Ain, N.U.; Bano, S.; Anis, I.; Anis, I.; Lubna; Faizi, S.; Bertino, M.F.; Naz, S.S. Green synthesis and molecular recognition ability of patuletin coated gold nanoparticles. Biosens. Bioelectron. 2015, 63, 499-505. [CrossRef]

39. Farhadi, F.; Khameneh, B.; Iranshahi, M.; Iranshahy, M. Antibacterial activity of flavonoids and their structure-activity relationship: An update review. Phytother. Res. 2018, 33, 13-40. [CrossRef]

40. Ali, H.; Uddin, S.; Jalal, S. Chemistry and Biological Activities of Berberis lyceum Royle. J. Biol. Act. Prod. Nat. 2015, 5, 295-312.

41. Jacob, A.E.; Hobbs, S.J. Conjugal Transfer of Plasmid-Borne Multiple Antibiotic Resistance in Streptococcus faecalis var. zymogenes. J. Bacteriol. 1974, 117, 360-372. [CrossRef]

42. Bajpai, P.; Kulshrestha, N.; Rafiee, J.; Koratkar, N.; Misra, D.S. Graphene Supported Platinum Nanoparticle Counter-Electrode for Enhanced Performance of Dye-Sensitized Solar Cells. Acs Appl. Mater. Interfaces 2011, 3, 3884-3889. [CrossRef]

43. Mir, M.A.; Sawhney, S.S.; Jassal, M.M.S. Qualitative and quantitative analysis of phytochemicals of Taraxacum officinale. Wudpecker J. Pharm. Pharmocology 2013, 2, 01-05.

44. Inalegwu, B.; Sodipo, O. Phytochemical screening and haemolytic activities of crude and purified saponins of aqueous and methanolic extracts of leaves of Tephrosia vogelii hook. F. Asian J. Plant Sci. Res. 2013, 3, 7-11.

45. Naz, S.S.; Islam, N.U.; Shah, M.R.; Alam, S.S.; Iqbal, Z.; Bertino, M.; Franzel, L.; Ahmed, A. Enhanced biocidal activity of Au nanoparticles synthesized in one pot using 2,4-dihydroxybenzene carbodithioic acid as a reducing and stabilizing agent. J. Nanobiotechnology 2013, 11, 13. [CrossRef]

46. Bauer, A.W.; Kirby, W.M.; Sherris, J.C.; Turck, M. Antibiotic susceptibility testing by a standardized single disk method. Am. J. Clin. Path. 1996, 45, 493-496. [CrossRef]

47. Muhammad, Z.; Raza, A.; Ghafoor, S.; Naeem, A.; Naz, S.S.; Riaz, S.; Ahmed, W.; Rana, N.F. PEG capped methotrexate silver nanoparticles for efficient anticancer activity and biocompatibility. Eur. J. Pharm. Sci. 2016, 91, 251-255. [CrossRef]

48. Pawlak, A.; Mucha, M. Thermogravimetric and FTIR studies of chitosan blends. Thermochim. Acta 2003, 396, 153-166. [CrossRef]

49. Cushnie, T.T.; Lamb, A.J. Antimicrobial activity of flavonoids. Int. J. Antimicrob. Agents 2005, 26, 343-356. [CrossRef]

50. Tungmunnithum, D.; Thongboonyou, A.; Pholboon, A.; Yangsabai, A. Flavonoids and Other Phenolic Compounds from Medicinal Plants for Pharmaceutical and Medical Aspects: An Overview. Medicines 2018, 5, 93. [CrossRef]

51. Gonelimali, F.D.; Lin, J.; Miao, W.; Xuan, J.; Charles, F.; Chen, M.; Hatab, S.R. Antimicrobial Properties and Mechanism of Action of Some Plant Extracts Against Food Pathogens and Spoilage Microorganisms. Front. Microbiol. 2018, 9, 1639. [CrossRef] 
52. Ogbole, O.O.; Akinleye, T.E.; Segun, P.A.; Faleye, T.C.; Adeniji, A.J. In vitro antiviral activity of twenty-seven medicinal plant extracts from Southwest Nigeria against three serotypes of echoviruses. Virol. J. 2018, 15, 110. [CrossRef]

53. Jaime, M.F.V.; Redko, F.; Muschietti, L.V.; Campos, R.H.; Martino, V.S.; Cavallaro, L.V. In vitro antiviral activity of plant extracts from Asteraceae medicinal plants. Virol. J. 2013, 10, 245. [CrossRef]

54. Park, H.-H.; Zhang, X.; Choi, Y.-J.; Park, H.-H.; Hill, R.H. Synthesis of Ag Nanostructures by Photochemical Reduction Using Citrate-Capped Pt Seeds. J. Nanomater. 2011, 2011, 1-7. [CrossRef]

55. Yadav, S.; Kumar. P. Production, isolation and identification of flavonoid from aerial parts of hiptage benghalensis. Int. J. Life Sci. Pharm. Res. 2012, 2, 1-5.

56. Bilia, A.R.; Isacchi, B.; Righeschi, C.; Guccione, C.; Bergonzi, M.C. Flavonoids Loaded in Nanocarriers: An Opportunity to Increase Oral Bioavailability and Bioefficacy. Food Nutr. Sci. 2014, 05, 1212-1327. [CrossRef]

57. Huang, H.; Lai, W.; Cui, M.; Liang, L.; Lin, Y.; Fang, Q.; Liu, Y.; Xie, L. An Evaluation of Blood Compatibility of Silver Nanoparticles. Sci. Rep. 2016, 6, 1-15.

(C) 2020 by the authors. Licensee MDPI, Basel, Switzerland. This article is an open access article distributed under the terms and conditions of the Creative Commons Attribution (CC BY) license (http://creativecommons.org/licenses/by/4.0/). 